Jones, L. Pastoral power and the promotion of self-care. Sociology of Health and Illness 2018. https://doi.org/10.1111/1467-9566.12736 


\title{
Pastoral power and the promotion of self-care
}

Lorelei Jones

\begin{abstract}
In many countries government policy is becoming increasingly reliant on citizens taking greater responsibility for their health and wellbeing and limiting their consumption of public services. In this paper I develop Foucauldian perspectives on the work required to create and maintain responsibilized subjects, focusing on the role of 'pastors' - specialists, experts and therapists who promote desirable subjectivities (Waring and Latif 2017). Drawing from ethnographic research, I consider how government policies for the promotion of self-care within the English healthcare system not only place increased emphasis on patients taking responsibility for their own health and wellbeing, but also seek to constitute new pastoral subjectivities as responsible for conducting the conduct of patients. I look at efforts to constitute pastoral subjectivities through an assemblage of management knowledge, educational practices and training materials. I argue that efforts to enrol and train pastors are unlikely to accomplish governmental objectives because of the availability of alternative guides for action drawn from professional training, established routines, and forms of social belonging.
\end{abstract}


The notion of 'self-care' has a long history in health care. It was, for example, a central tenet of the women's health movement which challenged the views of the medical profession and assumed that many aspects of health care could be performed by lay people (Boston Women's Health Book Collective 1976). Self-care is a dimension of both lay experiences and voluntary sector initiatives (Taylor and Bury 2007). In this paper I am primarily concerned with self-care as a dimension of national healthcare policy, and its subsequent enactment in local managerial strategies. As a dimension of national government policy, self-care aligns with prevailing discourses that constitute citizens as 'empowered', 'responsibilized' and 'activated' (Clarke 2005). In these discourses citizens are viewed as self-sustaining individuals making 'responsible' choices when consuming public services. In this paper I use empirical data to develop Foucauldian perspectives on the work required to create and maintain responsibilized subjects, focusing, in particular, on the role of 'pastors' (Foucault 1982).

I report findings from an ethnographic study that explored how the national policy objective of self-care was put into practice by local managers. I found a remarkably homogenous strategy across the four localities where I did fieldwork. In each case the aim of the strategy was to induce culture change in patients by 're-culturing' healthcare staff. This was attempted through a programme of ad hoc workshops to train relatively low status healthcare staff in new communicative strategies for patient interactions. I argue that this strategy is unlikely to be successful given the potential for alternative guides for action, for both healthcare professionals and patients. I discuss the implications of my findings for healthcare policy, and for theories of pastoral power and governmentality.

\section{Self-care in national healthcare policy}

The English Department of Health defines self-care as 'collaboratively helping individuals and their carers to develop the knowledge, skills and confidence to care for themselves and their condition effectively' (Department of Health 2005, p10). Self-care is central to the Department of Health's approach to addressing Long Term Conditions (Department of Health 2005), the government's Mandate for NHS England (Department of Health 2012), and NHS England strategy, as set out in the 'Five Year Forward View' (NHS England 2014). Examples of local initiatives to promote self-care include patient and carer education 
programmes, medicines management advice and support, advice and support about diet and exercise, use of telecare and telehealth to aid self-monitoring, and psychological interventions such as 'coaching'. The empirical data in this study relate to training programmes for nurses, therapists and other healthcare staff.

The policy antecedent for self-care is the Expert Patient Programme (Department of Health 1999, 2001). The Expert Patient Programme was initially imported from the US (Lorig et al 1996) and promoted in the UK by the charity Arthritis Care. In the Expert Patient Programme the patient is responsible for a number of tasks (box 1) and the aim of the programme is to provide patients with the skills to accomplish these tasks.

Box 1. The 12 self-management tasks in chronic disease. Source: Lorig et al (1996).

1. Recognising and responding to symptoms, including monitoring symptoms and controlling triggers to symptoms

2. Using medications

3. Managing acute episodes and emergencies

4. Maintaining good nutrition and an appropriate diet

5. Maintaining adequate physical exercise and an appropriate diet

6. Not smoking

7. Using relaxation and stress-reducing techniques

8. Interacting appropriately with health care providers

9. Seeking information and using community resources

10. Adapting work and other role functions

11. Communicating with significant others

12. Managing the negative emotions and psychological responses to illness

The notion of the 'expert patient' has been problematized by Lupton (1997) who argues that while the medical encounter involves information, it also involves embodiment and emotional features. Pain, illness and impending death may be highly emotional states whereby the person becomes dependent on others. In the literature it is not always clear to what extent patients value control, and empirical research has shown that efforts by healthcare staff to encourage patients to do things themselves are not experienced by patients 
as empowering, but as a request to fit in with staff needs and to 'co-operate' (Salmon and Hall 2003). The emphasis on 'empowerment' in policy discourse has also been criticised for focusing on individual behaviour, neglecting the structural and political determinants of health, and of accusing people who are poor or uneducated of 'causing' their own illness (Kronefeld 1979).

\section{Foucauldian perspectives on self-care policy}

The work of Foucault illuminates the many and varied forms of power, especially those that are difficult to see, such as the relations of power that are immanent in knowledge. Throughout his work, Foucault focuses on the mechanics of power in particular settings, explicating the multiple tactics, devices, and techniques of power. Sovereign power, exercised primarily through juridical institutions, is shown to be only one element among many, and works in part by inciting, reinforcing, monitoring, organizing and optimizing other forces (Foucault 1990).

As an alternative to formal authority, or crude force, 'pastoral power' works by encouraging obedient, self-governing subjects. Foucault's concept of pastoral power draws on Christian writings, particularly the biblical metaphor of the shepherd, and the Christian practice of confession. In Christian writings the image of the shepherd is used to describe the way that church leaders guide individuals and shape their moral conduct. The act of confession encourages the sinner to examine, and regulate, their thoughts and actions. They are aided in this task by the pastor who hears the confession. Foucault argues that the discursive ritual of confession has migrated from Christian communities to a range of domains, including the family, education and medicine, becoming integrated into state apparatus (Foucault 1990, p63). Across these different domains this obligatory speech act has taken on a variety of forms, including interrogations, consultations, and biographical narratives. In each case the confession unfolds within a power relationship (priest-parishioner, parent-child, teacherstudent, doctor-patient etc.). As confessional practices have spread, the scope has extended, from what an individual wished to hide, to what individuals hide from themselves and which can only be brought to light through the labour of confession, and with aid of the listener who works to decipher and interpret what the speaker is saying. While the objective in Christian communities was salvation in the next world, the objective within these new contexts is 
salvation in this world, where 'salvation' has come to be understood as health, wellbeing, security, or protection against accidents (Foucault 1982).

Applying the concept of pastoral power to healthcare policy, 'the modern pastorate' is made up of specialists, experts, and therapists who promote desirable subjectivities (Waring and Latif 2017). Waring and Latif develop the concept of pastoral power in an empirical study of the introduction of healthcare policies aimed at encouraging more adherent patients. These policies extend the role of pharmacists to monitoring medicines use and patient education. In this context Waring and Latif identify multiple pastors (GPs and pharmacists), whose practices are intended to influence the behaviour of patients, but who compete for legitimacy. Waring and Latif found that patients were active in resisting confessional accounts and expectations for greater responsibility. Patients would challenge professional advice, mobilising alternative understandings drawn from family, friends, and the media. Waring and Latif infer a considerable degree of strategic agency on the part of patients, for example, patients were seemingly aware of the difference in status between the GP and the pharmacist, and the competition between the two, and used this to enact their own influence. Both GPs and pharmacists appreciated the limits of their influence on patient behaviours, recognising that, as one respondent put it, 'you can talk to them for half an hour, they'll do exactly what they want when they get back home' (2017, p17).

Although previous studies have described the influence of pastors in the constitution of selfgoverning subjectivities (Rose 2007, Holmes 2002), there has been little attention to the pastors themselves, especially how they are discursively constituted and governed. In this paper I extend Waring and Latif's analytical focus on pastors to consider how government policies for the promotion of self-care within the English healthcare system not only place increased emphasis on patients taking responsibility for their own health and wellbeing, but seek to constitute new pastoral subjectivities responsible for guiding and shaping the conduct of patients. I locate pastors within a broader assemblage of government, made up of agents, texts, analyses, tactics and procedures. Foucault (1991) refers to this complex as 'governmentality'. The different components of this complex work together to discursively constitute and reinforce particular versions of political objects (such as 'health care'), and subjects, positioned within relations of power (such as 'doctors' and 'patients'). Within these assembled practices there is individual agency in a myriad of strategies and local objectives, however, the discursive effects of the assemblage exceed the intentions of individuals 
(Shapiro 1992). The hidden and indirect nature of these forces make them highly effective, yet there is always the potential for resistance as subjects seek more autonomous subject positions for themselves (Foucault 2011). There is also the potential for individual action to be influenced by alternative 'normative scaffolds', such as local traditions (Moreira 2013, p8).

I look at efforts to constitute self-care advisors through national policy, local service management, and the organisation and delivery of dedicated activities aimed at training healthcare professionals in self-care advice-giving and patient education. Through examining the interplay between policy discourse, management strategy, and educational activities, the paper develops new insight on the constitution of pastors, highlighting the underlying rationalities for pastoral work, and how expected pastoral practices conflict with underlying rationalities and subjectivities of care. As such, it contributes further conceptual understanding of the constitution of pastoral power within wider relations of power, especially the possibilities for pastors to be as much the subjects of disciplinary power as the mediums of self-care.

\section{Methods}

I develop a Foucauldian-inspired ethnographic approach that 'follows' a policy through multiple practices over time and space. I have been influenced by other scholars who have applied a governmentality lens to empirical studies of public policy, in particular Ball (2016) and Shore and Wright $(1997,2011)$. This approach explores how policy is articulated, enacted and experienced by multiple actors at different levels (national and local). It does not assume that concepts such as 'self-care' are imposed from central government to local agencies in a top down, unproblematic way, but rather sees such concepts as sites of struggles over meaning and implementation (Sharp and Richardson 2001).

An ethnographic focus on policy offers an analytically productive lens to study governmentality because of 'the way that policy creates links between agents, institutions, technologies and discourses and brings all these diverse elements into alignment' (Shore and Wright 2011, p11). I attempt an ethnography of assemblage that relates people, places, language and practices. I am interested in how discourses become assembled into a material 
reality, and the possibilities for relation and action this assemblage allows. My focus is on the operation of power through forms of knowledge, mundane practices, and artefacts (Foucault 1980), specifically, management knowledge, educational practices and training materials.

The topic emerged during fieldwork for a large study looking at how localities in England were implementing national policy aimed at promoting integration between health and social care (Erens et al 2015). I did fieldwork in four localities in four different regions of England between November 2013 and August 2015. During fieldwork I was struck by the way managers in each locality were implementing initiatives aimed at inducing 'culture change' to realise more self-care in the local population. I was also struck by the way the topic of selfcare appeared to elicit spontaneous confessions from informants with regards to their own behaviour. For example, during one meeting a local manager said, gesturing towards other colleagues who were present, 'we all self-care'. I wasn't sure what this meant at the time, but I wrote it down. How certain desirable self-understandings were articulated and promoted then became the focus of further data collection and analysis. National-level data includes policy documents and reports from national policy actors such as the Department of Health, national organisations representing other stakeholders such as staff and patient groups, policy think tanks, and academics. At the local level it comprises interview accounts from local health and social care managers $(n=53)$, meeting papers and other local policy and planning documents, and field notes from informal conversations, observation of planning meetings and participant observation of staff training. Interviews were semi-structured on the topic of implementation of national policy and explored local plans and how these were progressing at different points in time.

Interviews were recorded and transcribed in full. Observations were recorded as contemporaneous field notes in journals together with analytical memos. Consistent with my theoretical stance, I adopted a broadly discursive analytical strategy attuned to text and talk as social practices and the resources (interpretive repertoires, identities and category systems) drawn on by actors in those practices (Potter 1997). My strategy is informed by an ethnographic sensibility (Pader 2006) and a desire to remain open to emergent and unexpected findings, rather than impose an analytical framework a priori. Nonetheless, I entered the field sensitized to certain Foucaudian concepts, such as problematisations (definitions of problems, prescriptions, and how these are contested), technologies (techniques and interventions and how these are connected to larger assemblages), 
subjectivities (ontological, epistemological and ethical understandings of the self), and strategies (governmental aspirations) (Rose 1999). When it came to analysing my data I looked for regularities in the form of assumptions, categories, logics, and claims in relation to these concepts (Miller 1997). Data were coded by hand using the 'pencil and paper' method. This involved marking incidents of data I thought might be relevant to my emerging interpretative categories (Becker and Greer 1960). Coded data were compared and related to my theoretical interests to identify themes and to refine and elaborate my overall account of how concepts of self-care were put into practice by local government agencies.

The research was approved by the London School of Hygiene and Tropical Medicine Ethics Committee. It was exempt from NHS Research Ethics processes. However, reflecting on my study reveals some ethical tensions. My study is critical in the sense of being attuned to the operation of power. It is not intended to be critical of any particular individual or group. I was interested in what individuals did and said only so far as this constituted texts and practices which could be analysed so as to contribute to an understanding of the discursive origins, properties, and effects of a policy. Nonetheless, as Mosse (2006) has shown, an orientation to studying the general through the particular does not, in itself, guarantee that an ethnographic account will not be perceived by an informant as a source of personal offence. Creating an ethnographic account of policy involves making interpretations which participants, who have generously given of their time, may not share (Hastrup 2004). In line with standard research practice, I obtained consent from interviewees. I also obtained permission from local managers to attend, observe and make notes on meetings and workshops. I gave assurances to research participants that what was said during interviews would be kept in confidence and that data would be anonymized for individuals, organisations and localities.

\section{Findings}

Foucauldian approaches to studying public policy highlight the assemblage of agents, forms of knowledge, and activities, their articulation, and the way they align local practices with governmental objectives. I structure my findings under the following elements: Policy texts, management knowledge, local training programmes, and training materials. 


\section{Policy texts}

A prevalent narrative in policy texts, such as national policy documents and political speeches, was the financial imperative for self-care. This narrative often employed the managerial metaphor of the 'burning platform' to represent the problem of increasing demand and shrinking budgets. The proposed solution was a nation-wide culture change, so that people would self-care rather than use publicly funded services. This narrative is illustrated by the following extract from a blog post on the NHS England website. NHS England is a national policy making body. Although located at 'arms-length' from the central Department of Health, it is responsible for developing strategy for the NHS. The blog post was written by the lead for public participation, and posted to coincide with the publication of a think tank report on patient activation (Hibbard and Gilburt 2014):

If you listen to leading commentators working in the NHS, they say the future of the NHS depends on us addressing the grand challenges of the rise of the prevalence of long-term conditions and also the financial challenge. Given that long-term conditions are not curable, and can only be properly managed by patients self-managing and changing behaviours, we need to understand activation to address this challenge. Patient activation supports successful behaviour change, by building psychology into medicine in an elegant and practical way. Activation has major implications financially too. 70 per cent of the costs of the NHS are spent on people with long-term conditions. Studies show that major savings can be realised as activation increases and people selfmanage more effectively. (O’Shea 2014)

The financial rationale was tempered by an accompanying rationale that highlighted the benefit to patients, in terms of better health. These twin narratives, financial and patient benefit, were echoed in interview accounts with local healthcare managers. In these accounts the patient benefit narrative was often expressed as 'the right thing to do':

There were a couple of older ladies, members of the public, and I think that is going to be one of the more difficult things to do, is communicating to members of the public, the definition of self-care. It sounds like it is pushing responsibility onto the person, it sounds like it's just a money saving exercise. But I don't think it is. If you're activating 
someone, if they're looking after themselves, they'll be happy and healthier and more well, so to speak. (Local programme lead)

At both national and local levels there were multiple depictions of 'who' was required to practise self-care. While in some instances it was suggested that self-care was for 'everyone', at other times the target population was specified as people with long-term conditions, as in the NHS England blog post:

In England about 10 per cent or 1.5 million people with long-term conditions are in the lowest category of activation, lacking basic self-confidence, skills and a sense of selfefficacy. This means they will live without the sense of hope and resourcefulness that many of us take for granted. In the NHS we see them in our clinics every day, we give them loads of information, we tell them to stop smoking, but it simply doesn't work. (O’Shea 2014)

As noted earlier, the topic of self-care appeared to elicit confessions from individuals in relation to their own conduct. An example can be seen in one of the responses to the NHS England blog post, posted by a member of the public:

Being someone who has moved up the activation scale myself, since my diagnosis 19 years ago, this article resonates with me. As an activated self-manager I have healthier behaviours today than I did at diagnosis. I can be healthy and have MS. Yes I have knowledge, skills and confidence and I also have resilience because I know whatever this condition brings I can deal with it. That's where the psychology comes in...I am no longer frightened!

The author of this post is here identifying as an 'activated self-manager' who has improved over time, 'moving up the activation scale'. This extract illustrates the act of confession as a form of self-government that reinforces desirable subjectivities.

\section{Management knowledge}

Fieldwork offered the opportunity to explore how national self-care policy was implemented by local health and social care managers. In all four localities, local managers had introduced 
programmes aimed at changing the practices of healthcare professionals, or as one local workforce strategy document put it, 'the health and social care workforce will need to reculture'. Managerial strategies in the different localities were remarkably homogenous, involving training workshops for front-line staff to introduce the concept of self-care and to teach new communication techniques that staff could use with patients to encourage more self-care.

In developing and implementing self-care programmes, local managers drew on a small number of management texts, primarily reports published by policy 'thinks tanks'. Think tanks are civil society organisations that produce and disseminate knowledge related to public policy (Shaw et al 2014). In England they have become important policy actors, acting as 'transmission belts' for new policy ideas from the private sector and overseas (Alvarez and Mays 2008). These texts were repeatedly referred to in the interview accounts with managers, and in local planning documents, where they informed the rationale, logic, and form of selfcare initiatives. A key concept supplied by these management texts was 'patient activation'. Patient activation is a quantitative concept developed by the US academic Judith Hibbard and promoted in the UK by the policy think tank, the Kings Fund (Hibbard and Gilburt 2014). The following description of 'low' activation is from a Kings Fund report:

People who have low levels of activation are less likely to play an active role in staying healthy. They are less good at seeking help when they need it, at following a doctor's advice and at managing their health when they are no longer being treated. Their lack of confidence and their experience of failing to manage their health often means they prefer not to think about it. (Hibbard and Gilburt 2014, p3)

The Kings Fund report argues that individuals who are more activated are more likely to engage in healthy behaviours, 'like eating a healthy diet or taking regular exercise', and that activation will reduce healthcare costs by reducing hospitalisation and attendances at accident and emergency departments (Hibbard and Giburt 2014, p11).

Both the financial narrative and the patient benefit narrative, described earlier, coalesce around this concept of patient activation. The central position of this concept represents a discontinuity with the earlier emphasis on 'empowerment' in self-care discourses (Kronefeld 1979, Fox et al 2005). The concept of 'empowerment' implies a transfer of power. 
Activation, on the other hand, implies a docile being, requiring external force; an automaton in need of direction, in the form of medical expert knowledge and professional guidance. It suggests that certain people, lacking in some way, need to be managed for their own benefit. From a Foucauldian perspective, it is suggestive of the body as machine, requiring discipline and optimization of its capabilities, and as a potentially useful component of a broader machinery of cost control. At the same time, activation recognizes the body as a biological organism. It seeks to discipline the individual so as to control the biological processes that influence the level of health in the population. Activation is here also a causal postulate, indicating a particular paradigm or construction of illness as caused by absent, or insufficient, activation.

The concept of patient activation has been developed into a commercial product, the "patient activation measure' (Hibbard et al 2005). This tool identifies four possible levels of activation: (1) believes active role is important, (2) confidence and knowledge to take action, (3) taking action and, (4) staying the course under stress. The non-activated patient is defined as one who "may still believe that the doctor will "fix"' them' (2005, p1295). The patient activation measure was purchased by two of the localities in my study to use in local evaluations of self-care initiatives.

In all four localities organisations had based the design of their self-care programmes on a model developed by the Kings Fund known as 'the House of Care' (Coulter et al 2013). The House of Care is a 'reproducible and transferable delivery system' (p2). The aim of the model is to transform the relationship between patients and clinicians to one where the management of long term conditions is not the responsibility of the clinician but a 'collaborative endeavour with active patient involvement and effective self-management support' (p5). The model seeks to enable 'a new type of clinical consultation' which requires 'new skills and knowledge and new ways of thinking' (p 7) and 'culture change' (p7). The Kings Fund report acknowledges that this is a challenging task given the socialisation of clinicians into ways of working. Local health and social care commissioners are expected to lead efforts to introduce culture change in staff and patients. It suggests that 'skills workshops' could be used to train staff, although it is recognised that 'adhoc workshops or courses, however good, will not be sufficient to achieve measurable changes in practice' (p22), and that leadership from professional bodies is required. 


\section{Training programmes}

During fieldwork there were opportunities to attend some of the training workshops in one of the localities. The following account has been developed from field notes. At this time local organisations were implementing a locality-wide scheme to 'support local people to systematically manage their own conditions' (local planning document). Whilst the initiative was aimed at inducing culture change in both front-line staff and the public, at the time of fieldwork the 'public' element was not very well developed. The manager leading on the initiative said he was unsure of how, exactly, to implement this aspect of self-care, aside from 'some sort of social marketing'. Rather, at this stage, the initiative relied on training staff to encourage patients to have different expectations. In contrast, the element aimed at inducing culture change in staff was well underway and comprised a staff training programme consisting of the following elements: (i) initial 'firestarter' workshop; (ii) skills workshops; (iii) action learning using change champions to sustain change.

The initial 'firestarter' workshop was held in a community hall. It was an example of what is sometimes referred to in the management and organisational studies literature as 'facilitation' (Kislov et al 2017). Facilitation, broadly defined, is as an approach to developing learning processes in group contexts. It is characteristically orientated to encouraging others to reflect upon their current practices in order to identify gaps in performance and introduce change. During an informal conversation with the facilitator after the workshop, he explained that the aim of the initial workshop was to 'introduce the self-care philosophy'. The session relied on creating a 'light bulb moment' when participants realise that, contrary to what they already thought, they were not 'doing it already'. This account echoed, nearly word for word, the Kings Fund report on the 'House of Care', illustrating the influence of management knowledge on practice. The facilitator explained how the idea was to deliberately recruit 'early adopters' rather than 'laggards'. The intention was that these individuals would return to their organisations, enthusiastic and eager to spread the message to colleagues, thus creating a 'ripple effect'.

The workshop I attended comprised the typical activities and artefacts of facilitation, a designated 'facilitator', flip charts, and a combination of plenary sessions and small-group exercises. On the day I attended there were 30 participants seated around six tables. Participants were a combination of community and district nurses, therapists, members of the 
voluntary sector and local residents. I was seated at a table with two community matrons, an occupational therapist and a dietician. During the workshop each table worked as a small group on various exercises. The first session was called 'self-care - what are we talking about?'. This was a 'brainstorming' session, whereby the facilitator would ask a question and each table would write down answers. The entire group then reconvened to report their answers and these were recorded on a flip chart. The following questions and answers are taken from field notes:

Facilitator: What is the opposite of self-care?

Answers from participants: 'Risk-taking', 'relying on other people'

Facilitator: What stops you looking after yourself?

Answers from participants: 'Lethargy', 'lack of motivation'

There are many possible answers to the questions posed by the facilitator (my own response to the question 'what is the opposite of self-care?' was 'care'). What struck me about the responses that were given by participants was the underlying moralism. In these narratives illness is caused by a failure to self-care. If self-care is being pursued here as a positive action, then the opposite, relying on other people, must be negative. It becomes, as a workshop participant makes explicit in the extract below, 'a problem':

The problem is the attitude that 'I'll do what I like, drink what I like, eat what I like, because someone will sort it out for me'.

This narrative constructs 'the good self' - independent, motivated, and responsible. In these accounts bad choices result from 'the wilfulness of irresponsible people, rather than the structural distribution of resources, capacities and opportunities' (Clarke 2005, p451). 'The problem' in this narrative, is an expectation from patients that if they are unwell a doctor will fix them. While this problem construction was repeated in my data, for example in the interview accounts of local managers, and in management texts, it is not consistent in the NHS. For example, when I was writing this paper I noticed in the waiting room of my own GP surgery a poster advertising osteopathy services. It said: 
If your car broke down you'd take it to a mechanic. If your pipe leaked you'd call a plumber. If your laptop malfunctioned you'd seek help from an IT engineer...So if pain in your muscles and joints is stopping you working, see an expert, visit an osteopath.

This poster illustrates the availability of alternative and competing subject positions and versions of health care, for example, the patient as a machine in need of repair, or a consumer making a rational decision to seek help from an expert.

The purpose of the second workshop was to teach healthcare staff skills in inducing more self-care in patients. This comprised training in 'motivational interviewing', an approach to communicating with patients aimed at changing behaviour (Miller and Rollnick 2012). Like the first workshop, it was attended by staff of a relatively low status in the NHS hierarchy, primarily community nurses and therapists. The workshops were based on the premise that when staff returned to their work they would use these techniques in clinical encounters with patients.

As with the first workshop, the skills workshop was held in a community hall with approximately 30 people arranged in small groups seated at tables. The workshop comprised a slide presentation, interspersed with exercises on worksheets, followed by a skills rehearsal. The aim was to teach participants how to have 'different conversations' with patients. Participants were encouraged to ask open questions, to listen, and to summarise the patient's response, and were supplied with suggested phrasings to do this. The ideal conversation would follow four stages: (1) share ideas, (2) compare the benefits (3) discuss ideas and (4) make a plan. The training session concluded with participants writing down their own 'action statements'. These were commitments to take action after they leave the session, for example 'I will use the techniques I learnt today in future consultations with patients'. These statements were then shared with the group and recorded on a flip chart.

Both workshops can be seen to take the format of the confession. Through ritual speech acts staff are guided by the facilitator to reflect on existing practice and to come to the realisation, contrary to their prior self-understanding, that they had not been doing 'the right thing'. Having seen the error of their ways, attendees were required to commit to different behaviours in the future. Staff were also trained to repeat the confessional format in consultations so as to encourage patients to adopt desirable subjectivities as responsibilized 
citizens. For both patients and pastors these workshops form part of a technology of the self, engendering particular ways of thinking, judging and acting on the self (Rose 1999).

Although responses from participants in the first workshop suggested a ready acceptance of the discourse among participants (the intentionally recruited 'early adopters'), in the second workshop there was some resistance from participants, who argued that the proposals were not relevant to their practice:

I work with people with dementia so realistically I don't think this will work (workshop participant)

I work in elderly care and I don't like the health promotion. I think it is patronizing. I think this person has got to this age, they are probably thinking, who am I to tell them? (workshop participant)

\section{Training materials}

The initial workshop included a session called 'what would self-care look like for the people of (locality A)'? Groups were provided with handouts consisting of several 'pen portraits' of individuals, couples, and families, illustrated with photographs. These gave a brief description of the individuals (name, age, sex, employment and so forth), and their behaviour. In this way they resembled the use of medical cases as a teaching tool for medical students, containing superficial accounts of potentially relevant patient characteristics and healthrelated behaviour for the purposes of diagnosis and prescription. The objective of this session was for participants to discuss what self-care might look like for these individuals.

Some digging around online after the workshop revealed that the pen portraits were based on the Healthy Foundations Lifestages Segmentation (Williams et al 2011), a market segmentation model based on different levels of motivation, published by the Department of Health for use with behaviour change programmes in the NHS. For example, in one portrait the 'health motivation profile' of an older couple 'Elsie and Arnold', was said to be 'unconfident fatalists'. The characteristics of this segment, as presented on the handout, are given in box 2 .

Box 2. Unconfident Fatalists. Source: Training materials, staff training workshop. 
Profile:

Segment with an older average age

Tend to live in the most deprived areas

Least likely to be in paid work

More likely to be retired

Behaviours

Exhibit the most negative health behaviours

Hold negative perceptions about a healthy lifestyle

Often fatalistic about their health

Market segmentation models have been critiqued for providing static and skeletal descriptions of a shifting and complex reality (Cuciurean-Zaplan 2014). They also fail to account for the political context of behaviours, and the way that identity and class are performed through health behaviours (Bourdieu 1986). These models are not neutral but reproduce assumptions about their subjects (Cuciurean-Zaplan 2014), in this case, as lazy, risk-takers, culpable in their own ill health, and lacking in requisite skills and motivations.

There are two features of the pen portraits that were used in the workshop that are worth noting here. The first is that all the individuals were well. Their relevance to the staff participating in the workshop was that the subjects exhibited behaviours (drinking alcohol, smoking) that might lead them to become unwell, and as a consequence, use health services, in the future. Thus one reading of these training materials is as manifesting the extension of the medical gaze, and the pre-illness 'at risk' state as the focus of medical intervention (Armstrong 1995). Yet, in this respect, the pen portraits diverged from the kind of patients the staff who were present saw in their day-to-day work. Indeed on a number of occasions during fieldwork there were suggestions from staff that the acuity of their case-load had increased, as pressure on budgets resulted in rising access thresholds. And during one interview a manager observed that a local programme evaluation had been hindered by the fact that there were no patients who were well enough to be interviewed by researchers.

The second observation is that all the individuals in the pen portraits were economically deprived, although there was no attempt to link this characteristic to others (motivations, 
beliefs and behaviours). The segments in the Healthy Foundations Lifestages Segmentation model are defined by levels of motivations, beliefs and health-related behaviours, abstracted from social and cultural context. The association with markers of socio-economic deprivation is presented as incidental, as if discovered from the research, as almost surprising. For example, in the profile of the 'unconfident fatalists' it is observed that they 'tend to live in the most deprived areas'. In the workshops the population of interest was not 'everyone' or 'people with long term conditions' but 'the poor'. However, while the population is defined by structural factors, the only levers that are identified for professionals are personal attributes, specifically, 'motivation'. And it is the responsibility of the patient to become more motivated. As such the discourse is based on what Kronenfeld calls 'old ideologies that the poor are poor, sick, or unhappy because they do not try' (Kronenfeld 1979, p266). These features are illustrated in the portrait for 'Ben and Tracy' (Box 3).

Box 3. 'Ben and Tracy'. Source: Training materials, staff training workshop.

Sharon is originally from Birmingham and moved here when she met Mark and married him 16 years ago. She is Ben (14) and Tracy's (12) mum and is now a single parent since Mark died suddenly 2 years ago. Mark didn't get on with his family and she has no family close by. She works full time at Asda so Ben and Tracy have to let themselves in after school - she always leaves a snack to tide them over till she gets in to make dinner. Ben's got in with an older crowd and has started skipping school to hang out at the local skate park - dragging Tracy with him. She knows Ben's drinking and suspects he's smoking weed, she worries that Tracy will copy him as she idolises him. Sharon's tried everything to get Ben back on track but nothing seems to work and she's at her wits end. She can't afford to leave her job or pay for afterschool clubs and doesn't know where to turn. When she lived in Birmingham a good friend lost her children to the care system and she's terrified to contact anyone in case it happens to her.

When I read the handout I felt empathy for the fictional Sharon. I imagined she felt ground down by the relentless demands of school aged children, and exhausted from long days spent combining paid work with childcare and domestic labour. Sharon's socio-economic position is clearly signalled by her job at 'Asda', a supermarket whose clientele is predominantly those on low income, and this was reinforced by the accompanying photograph of three children, wearing baseball caps and 'hoodies', one drinking from a can of beer, against a back 
drop of graffiti. There is an implicit condemnation of Sharon in the reference to 'latchkey' children. I could think of various national and community-level interventions that could potentially improve her quality of life, higher minimum wage, interventions aimed at maximising uptake of state benefits, subsidised child-care, community facilities and services that provide instrumental social support and alternative activities for her children, yet staff were guided to see the remedy for Sharon's concerns as self-care.

\section{Discussion}

Self-care policies illustrate a contemporary form of government that works through an assemblage of expert knowledge and activities to constitute political objects and subjectivities. Policy makers, policy documents, national managers, academics, think tanks, management knowledge, local managers, managerial strategies, educational practices, training materials, and healthcare professionals, are brought together by self-care policy to shape the conduct of citizens. My focus in this study was on the practices through which pastors were enrolled and trained to promote and maintain responsibilized subjects. I found that across four different geographical localities in England local managerial strategies for implementing self-care were remarkably homogenous, both in terms of conceptual frameworks, and the use of workshops for training healthcare staff. This homogeneity was produced by the isomorphic effects of management knowledge (DiMaggio and Powell 1983). Ferlie et al (2016) characterise management knowledge as normative in tone, closely linked to a proposed solution, less theoretical than traditional academic writing, focused on enhancing organisational performance, and addressing 'hot' issues in public policy (Ferlie et al 2016). Management knowledge circulates, facilitated by well-packaged and labelled models and techniques that can travel easily between settings and spheres (Sahlin-Anderson and Engwall, 2002). These products contributed key concepts, framings, and guidance on how self-care should be implemented in local contexts, and had an observable influence on local management practice.

All four localities in my study had introduced training programmes which aimed to induce culture-change. Ferlie (2016) detects an increased use of educational technologies, such as training, leadership development programmes, mentors, action learning sets, and coaches, to produce active change agents. These technologies encourage personal development and 
'growth', but in a direction that is aligned with the national policy agenda. Ferlie argues that these 'soft' forms of power are becoming increasingly important in organisational settings, replacing, or used alongside of, performance management. In my study healthcare professionals were being trained to instil and maintain new self-managing subjectivities in patients by employing different communicative strategies.

There are a number of reasons why these efforts may not be successful in accomplishing governmental objectives. The training is provided in short sessions on an ad hoc basis, in contrast to professional training where socialisation into professional identities is accomplished through many years of education and apprenticeship. It is also provided to staff with established roles and routines. Thus new professional subjectivities must compete with self-understandings and practices that have built up over many years. The sociology of the professions suggests that healthcare identities are not simply ascribed in roles, such as 'nurse', but must be achieved through 'the routines, relationships and rituals of everyday practice' (Waring and Bishop 2011, p 664), which is one reason why clinical practice is often resistant to change. Previous research on managerial efforts to introduce changes to clinical practice has found that these have struggled to become embedded as staff return to preexiting roles and relationships (Waring and Bishop 2010). In addition, training is provided to staff relatively low down the NHS hierarchy, such as district and community nurses, dieticians and occupational therapists. Although all localities were also providing training in motivational interviewing for GPs, there remains the potential for these attempts to introduce new cultural practices to be displaced by conflicting practices of higher status members of staff, such as hospital consultants, who may still believe that they can 'fix' the patient.

Efforts to re-culture patients may also face resistance from patients themselves, as found by Waring and Latif (2017) or they may compete with alternative foundations for action, such as family roles or cultural heritage. An independent evaluation of the Expert Patient Programme found no effect on levels of service utilisation (Gately et al 2007). This was attributed to the fact that the programme reinforced people's pre-existing self-management strategies, rather than initiating behaviour change. Gately et al found that people's patterns of using services had developed over many years and were strongly influenced by the supply side, such as entrenched forms of health service organisation relating to procedures for ordering tests, routine monitoring, and repeat prescriptions. A limitation of my study was that I did not observe subsequent staff-patient interactions. Future research might therefore fruitfully 
explore to what extent the behaviour of staff and patients is shaped by these new subjectivities.

Self-care policy constructs 'the good self', independent, active and responsible. Motivations, beliefs and behaviours are depicted as free floating, rather than symptomatic of physical or mental illness, injury, the experience of violence or trauma, or ineffable social suffering (Redley 2003, Wilkinson 2004), experiences which are themselves grounded in the economic system and its consequences for power relationships and the distribution of material resources. In self-care narratives, low levels of activation are the cause of illness. Interventions are therefore aimed at 'activating' the patient. However, as Salmon and Hall observe, 'in ordinary life the language of 'failure to cope' is used widely to indicate distress' (2003, p1974). The result is a circular argument that suggests that people's lives would be better if only people's lives were better. Self-care narratives also assume an individual rational actor, neglecting 'the social life of decisions' (Rapley 2008), and the ontology of health behaviours as expressions of social belonging (Wolf-Meyer and Callahan-Kapoor 2016).

As a dimension of national healthcare policy, self-care reflects the trend for government to focus on behaviour modification, and short term individual action, rather than 'upstream' forms of intervention (National Institute for Health and Care Excellence 2007), despite evidence that individual-level interventions are largely ineffective, and despite widespread academic attention to the fundamental role played by inequalities in power and material resources in health outcomes (Marmot 2010). Scott-Samuel and Smith (2015) refer to this as 'utopian' healthcare policy, in the sense of 'a fantastical impossible dream which will almost certainly not come to fruition' (2015, p422). They attribute utopian policies to neoliberal governments committed to 'rolling back the state', and to free-market oriented economic policies. Self-care may bring benefits to both patients and professionals, but as a dimension of social policy it is utopian in the belief that re-culturing the public will significantly reduce demand on statutory services, and that organisations in local health and social care markets will respond to a reduction in demand by reducing supply and closing facilities so as to produce 'significant cost savings' (rather than, say, lowering access thresholds).

Waring and Latif's (2017) study highlights how the variegation of the discursive field makes governmentality fragile. In my study alternative subjectivities and ontologies of care were 
available to both staff and patients through socialisation into professional roles and enduring patterns of consultation. Another potential source of competing discourse is private sector providers. Private sector providers are increasingly used to provide healthcare services to NHS patients. In offering alternative understandings of health care, the consumer, and the professional-patient relationship (as illustrated in my study by the example of osteopathy services), they may undermine national policy objectives for more self-care.

Self-care policy illustrates the governmentalisation of expertise. By this I mean the enrolment of experts, and the mobilisation of expert knowledge and activities, to accomplish governmental objectives. If, as Waring and Latif suggest, patients recognise and resist statesponsored subjectivities and expectations, this could potentially erode trust in public-sector clinicians and threaten their legitimacy.

\section{Conclusion}

Drawing on Foucauldian perspectives I explored how local government agents implemented national self-care policy. I described a homogenous managerial strategy aimed at 'reculturing' the public through 're-culturing' healthcare staff. This strategy is aimed at providing skills training to staff to enable them to instil and maintain responsibilized subjectivities through new and different communicative responses. This strategy, however, leaves a significant space for the conduct of staff and patients to be shaped by alternative guides for action drawn from professional training, established routines, and forms of social belonging. More research is needed to explore the effects of the interaction of self-care discourses with situated agency in particular empirical contexts.

\section{Acknowledgements}

I am grateful to the managers who generously gave of their time to be interviewed for this study, and to two anonymous reviewers for helpful comments.

This research was funded by the Policy Research Programme of the Department of Health for England, via its core support for the Policy Innovation Research Unit. Lorelei Jones was (in 
part) supported by the National Institute for Health Research (NIHR) Collaboration for Leadership in Applied Health Research and Care (CLAHRC) North Thames at Bart's Health NHS Trust. The views expressed are those of the author and not necessarily those of the NHS, the NIHR or the Department of Health and Social Care.

\section{References}

Alvarez-Rosete, A. and Mays, N. (2008) Reconciling two conflicting tales of the English health policy process since 1997, British Politics, 3, 2, 183-203.

Armstrong, D. (1995) The rise of surveillance medicine. Sociology of Health and Illness, 17, 3, 393-404.

Ball, S. (2016) Following policy: Networks, network ethnography and education policy mobilities. Journal of Education Policy, 31(5), 549-566.

Becker, H. and Greer, B. (1960) Participant observation: The analysis of qualitative field data. In Adams, R. and Preiss, J. (eds) Human organisation research: Field relations and techniques. Homewood, IL, Dorsey Press.

Boston Women's Health Book Collective. (1971) Our bodies, Our Selves. New York, Simon and Schuster.

Bourdieu, P. (1986) The forms of capital. In Richardson, J. (ed.) Handbook of Theory and Research for the Sociology of Education. New York, Greenwood.

Clarke, J. (2005) New Labour's citizens: activated, empowered, responsibilized, abandoned? Critical Social Policy, 25, 4, 447-463.

Coulter, A., Roberts, S., and Dixon, A. (2013) Delivering Better Services for People with Long-term Conditions. Building the House of Care. London, The King's Fund. 
Cuciurean-Zapan, M. (2014) Consulting against culture: A politicised approach to segmentation. Ethnographic Praxis in Industry Conference, 1, 133-146.

Department of Health. (1999) Our Healthier Nation - Saving Lives. London, The Stationary Office.

Department of Health. (2001) The Expert Patient: A New Approach to Chronic Disease Management for the 21st century. London, Department of Health.

Department of Health. (2005) Supporting People with Long Term Conditions. London, Department of Health.

Department of Health. (2012) The Government's Mandate for NHS England 2016-17. London, Department of Health.

DiMaggio, P., and Powell, W. (1983) The iron cage revisited: Collective rationality and institutional isomorphism in organizational fields. American Sociological Review, 48, 2, 147 160.

Erens, B., Wistow, G., Mounier-Jack, S., Douglas, N., Jones, L., Manacorda, T., and Mays, N. (2015) Early Evaluation of the Integrated Care and Support Pioneers. London, Policy Innovation Research Unit.

Ferlie, E., (2016) Analysing Health Care Organizations. A Personal Anthology. London, Routledge

Ferlie, E., Ledger, J., Dopson, S., Fischer, M., Fitzgerald, L., McGivern, G., and Bennett, C. (2016) The political economy of management knowledge: Management texts in English healthcare organizations. Public Administration, 94,1,185-203.

Foucault, M. (1980) Power/Knowledge: Selected interviews and other writings 1972-1977. Edited by Gordon, C. New York, Pantheon.

Foucault, M. (1982) The Subject and Power. Critical Inquiry 8,4, 777-95. 
Foucault, M. (1990) The history of sexuality. Volume 1: An Introduction. New York, Vintage.

Foucault, M. (1991) Governmentality. In Burchell, G., Gordon, C., and Miller, P. (eds), The Foucault Effect. Chicago, The University of Chicago Press.

Foucault, M. (2011) The Government of the Self and Others. London, Palgrave-Macmillan.

Fox, N., Ward, K., and O'Rourke, A. (2005) The 'expert patient': empowerment or medical dominance? The case of weight loss, pharmaceutical drugs and the internet. Social Science and Medicine, 60, 6, 1299-1309.

Gately, C., Rogers, A., and Sanders, C. (2007) Re-thinking the relationship between longterm condition self-management education and the utilisation of health services. Social Science and Medicine, 65, 5, 934-945.

Hastrup, K. (2004) Getting it right: knowledge and evidence in anthropology. Anthropological Theory, 4, 455-472.

Hibbard, J., Mahoney, E., Stockard, J., and Tusler, M. (2005) Development and testing of a short form of the patient activation measure. Health Services Research, 40, 1918-1930.

Hibbard, J. and Gilburt, H. (2014) Supporting people to manage their health: an introduction to patient activation. London, The Kings Fund.

Holmes, D. (2002) Police and pastoral power: Governmentality and correctional forensic psychiatric nursing. Nursing Inquiry 9(2):84-92.

Kislov, R., Humphreys, J., and Harvey, G. (2016) How do managerial techniques evolve over time? The distortion of "facilitation" in healthcare service improvement. Public Management Review, 1-19. doi:10.1080/14719037.2016.1266022 
Kronenfeld, J. (1979) Self care as a panacea for the ills of the health care system: an assessment. Social Science and Medicine. Part A: Medical Psychology and Medical Sociology, 13, 263-267.

Lorig, K., Stewart, A., Ritter, P., Gonzàlez, V., Laurent, D. and Lynch, J. (1996) Outcome measures for health education and other health care interventions. Thousand Oaks: Sage.

Lupton, D. (1997) Consumerism, reflexivity and the medical encounter. Social Science and Medicine 45, 3, 373-381.

Marmot, M. (2010) Fair Society, Healthy Lives. Strategic Review of Health Inequalities in England Post-2010.

Miller, G. (1997). Building bridges: The possibility of analytic dialogue between ethnography, conversation analysis and Foucault. In Silverman, D. (ed.), Qualitative Research. Theory, Method, Practice. London, Sage, pp. 24-44.

Miller, W. and Rollnick, S. (2012) Motivational Interviewing: Helping People Change. New York, Guilford Press.

Mosse, D. (2006) Anti-social anthropology? Objectivity, objection, and the ethnography of public policy and professional communities. Journal of the Royal Anthropological Institute, $12,935-956$.

Moreira, T. (2013) The Transformation of Contemporary Health Care: The Market, the Laboratory, and the Forum. London, Routledge.

National Institute for Health and Care Excellence. (2007) Behaviour change: general approaches. Public Health Guideline. London, National Institute for Health and Social Care Excellence.

NHS England. (2014) Five Year Forward View. 
O’Shea, L. (2014) Is the NHS missing a vital sign? NHS England guest blog 16 May. https://www.england.nhs.uk/2014/05/luke-oshea-2/

Pader, E. (2006) Seeing with an ethnographic sensibility: Explorations beneath the surface of public policies. In Yanow, D., and Schwartz-Shea, P. (eds) Interpretation and method: empirical research methods and the interpretive turn. Armonk, NY, M.E.Sharpe, pp. 161-174.

Potter, J. (1997) Discourse analysis as a way of analysing naturally occurring talk. In Silverman, D. (ed.) Qualitative Research. London, Sage, pp. 200-222.

Rapley, T. (2008) Distributed decision making: the anatomy of decisions-in-action. Sociology of Health and Illness, 30, 3, 429-444.

Redley, M. (2003) Towards a new perspective on deliberate self-harm in an area of multiple deprivation. Sociology of Health and Illness, 25,4, 348-372.

Rollnick, S., and Miller, W. (1995) What is motivational interviewing? Behavioural and Cognitive Psychotherapy, 23,4, 325-334.

Rose, N. (1999) Governing the Soul: The Shaping of the Private Self. London, Free Association Books, 1999.

Rose, N. (2007) The politics of Life Itself. Oxford, Princeton.

Sahlin-Anderson, K. and Engwall, L. (2002) Carriers, flows and sources of management knowledge. In Sahlin-Anderson, K. and Engwall, L. (eds) The Expansion of Management Knowledge. Stanford, Stanford University Press.

Salmon, P. and Hall, G. (2003) Patient empowerment and control: a psychological discourse in the service of medicine. Social Science and Medicine 57, 1969-1980.

Scott-Samuel, A., and Smith, K. (2015) Fantasy paradigms of health inequalities: Utopian thinking? Social Theory and Health, 13, 3-4, 418-436. 
Shapiro, M. (1992). Reading the postmodern polity. Minneapolis, University of Minnesota Press.

Sharp, L., and Richardson, T. (2001) Reflections on Foucauldian discourse analysis in planning and environmental policy research. Journal of Environmental Policy and Planning, 3,3, 193-209.

Shaw, S., Russell, J., Greenhalgh, T., and Korica, M. (2014) Thinking about think tanks in health care: a call for a new research agenda. Sociology of Health and Illness, 36, 3, 447-461.

Shore, C. and Wright, S. (1997) Policy: A new field of anthropology. In Shore, C. and Wright, S. (eds) Anthropology of Policy. Oxon, Routledge.

Shore, C., and Wright, S. (2011) Conceptualising policy: technologies of governance and the politics of visibility. In Shore, C., Wright, S., and Però, D. (eds), Policy Worlds: Anthropology and the Analysis of Contemporary Power. Oxford, Berghahn Books, pp. 1-26.

Taylor, D. and Bury, M. (2007) Chronic illness, expert patients and care transition. Sociology of Health and Illness, 29,1, 27-45.

Waring, J., and Bishop, S. (2010) Lean healthcare: rhetoric, ritual and resistance. Social Science and Medicine 71(7), 1332-1340.

Waring, J., and Bishop, S. (2011) Healthcare identities at the crossroads of service modernisation: the transfer of NHS clinicians to the independent sector? Sociology of Health and Illness, 33,5, 661-676.

Waring, J. and Latif, A. (2017) Of shepherds, sheep and sheepdogs? Governing the adherent self through complementary and competing 'pastorates'. Sociology. DOI: https://doi.org/10.1177/0038038517690680

Wilkinson, I. (2004) The problem of 'social suffering': The challenge to social science. Health Sociology Review, 13,2, 113-121. 
Williams, B., McVey, D., Davies, L. and MacGregor, E. (2011) The Healthy Foundations Lifestages Segmentation: Research Report No. 1: Creating the segmentation using a quantitative survey of the general population of England. London, Department of Health.

Wolf-Meyer, M., and Callahan-Kapoor, C. (2016) Chronic subjunctivity, or, how physicians use diabetes and insomnia to manage futures in the United States. Medical Anthropology, 113. 